\title{
Práticas corporais e meditativas: Educação Física à margem?
}

\author{
Physical and meditative practices: Physical \\ Education on the sidelines?
}

\author{
Prácticas corporales y meditativas: Educación \\ Física al margen?
}

Rogério Cruz de Oliveira 1

doi: 10.1590/0102-311X00074718

As políticas de saúde no Brasil têm privilegiado as práticas corporais em suas mais diversas ações. De certo modo, isso é fruto da valorização do corpo e do movimento como estratégias de produção de cuidado em saúde face ao hegemônico ideário prescritivo e curativo. Assim, não raro, tem sido cada vez mais frequente acessar produções científicas que busquem investigar o fenômeno das práticas corporais e da saúde por um prisma ampliado, que é o caso do artigo Contribuições e Desafios das Práticas Corporais e Meditativas à Promoção da Saúde na Rede Pública de Atenção Primária do Município de São Paulo, Brasil 1.

O manuscrito, fruto de tese de doutorado, objetivou compreender como as práticas corporais e meditativas são produzidas, vivenciadas e apropriadas pelos diferentes sujeitos envolvidos no cuidado. Para tanto, desenvolveu um estudo qualitativo em 16 unidades de saúde do Município de São Paulo, Brasil, tendo entrevistado 29 profissionais e 36 participantes.

Com referencial teórico calcado na saúde coletiva e sociologia, os autores discorrem sobre o campo conceitual, histórico, político e pedagógico das práticas corporais e meditativas no campo da saúde, ofertando ao leitor uma sólida contextualização. Nessa esteira, os resultados e a discussão dos dados coletados conduzem a argumentos irrefutáveis sobre a seguinte compreensão: as práticas corporais e meditativas, ao ampliar o seu escopo para além da dimensão orgânico-funcional, permitem a existência de uma prática terapêutica coerente com a Política Nacional de Promoção da Saúde (PNPS), sobretudo no que se refere ao empoderamento, ao holismo e à participação social. Entretanto, também concluem que a existência de dificuldades no campo da intersetorialidade e das ações multiestratégicas exploram pouco o potencial da PNPS, conclusão que também endosso.

Contudo, um dado não explorado pelos autores salta aos olhos: o fato de apenas dois profissionais de Educação Física serem responsáveis por grupos de práticas corporais e meditativas num universo de 41 outros profissionais. Como um profissional com tão íntima formação nas questões ligadas ao corpo e ao movimento pode ter participação inexpressiva na saúde? Ao menos uma reflexão é possível: ao ser oficialmente vinculada com a saúde em 1997, por meio da Portaria no 218/1997 2, é notório salientar que a Educação Física ainda trilha um caminho de legitimação que outras profissões já superaram. Nesse sentido, a inserção profissional da Educação Física no Sistema Único de Saúde ainda é escassa e de baixa representatividade 3. Com a Educação Física à margem da discussão e da intervenção na oferta das práticas, a PNPS tem abreviado seu potencial de produção de cuidado. Não
1 Universidade Federal de São Paulo, Santos, Brasil.

Correspondência R. C. Oliveira Universidade Federal de São Paulo. Rua Silva Jardim 136, Santos, SP 11015-020, Brasil. rogerio.unifesp@gmail.com 
por incapacidade das outras profissões, mas pela não presença massiva de profissionais de Educação Física que poderiam ampliar o olhar sobre as práticas corporais e meditativas nesse campo. Isso não significa que há aqui uma defesa de que a simples presença do profissional de Educação Física superaria os limites apontados no estudo de Galvanese et al. 1. Mas, hipoteticamente, as possibilidades intersetoriais poderiam ser mais bem equacionadas, haja vista, por exemplo, que as secretarias de esporte dos municípios, historicamente, têm desenvolvido ações no âmbito do esporte-saúde-qualidade de vida, que, sob outra "pasta/égide" - a do fenômeno esportivo -, possui limitações que não se superam sozinhas.

Em síntese, a produção de cuidado em saúde no campo das práticas corporais e meditativas não pode ser vista só pelas secretarias de saúde, mas por ações intersetoriais que fomentem a “...ampliação das redes de convivência e do acesso a bens culturais..." 1 (p. 6). Nesse sentido, a Educação Física como área cara ao tema carece de um duplo movimento: ser chamada ao diálogo e, concomitantemente, requerê-lo. Sem dúvida, haveria uma melhor perspectiva.

1. Galvanese ATC, Barros NF, d'Oliveira AFPL. Contribuições e desafios das práticas corporais e meditativas à promoção da saúde na rede pública de atenção primária do Município de São Paulo, Brasil. Cad Saúde Pública 2017; 33:e00122016.

2. Ministério da Saúde. Resolução no 218, de 6 de março de 1997. Reconhecimento de profissionais de saúde de nível superior. Diário Oficial da República Federativa do Brasil 1997; 5 mai.
3. Candido LO, Rossit RAS, Oliveira RC. Inserção profissional dos egressos de um curso de Educação Física com ênfase na formação em saúde. Trab Educ Saúde 2018; 16:305-18. 